\title{
Què passa amb els aliments després de la seva digestió?
}

\author{
Muntsa Bigas Baqué (CDECT) \\ bbmuntsa@yahoo.es \\ Mariona Domènech Girbau (CDECT) \\ mdomen11@xtec.cat
}

Presentem tres activitats didàctiques complementàries, pensades per a alumnes de batxiIlerat, que pretenen estudiar el procés de digestió i d'absorció de nutrients al budell prim, des del nivell macroscòpic d'òrgan (pràctica de laboratori) al nivell molecular (simulació), tot considerant el procés de "parlar ciència" a través d'una activitat d'estructuració i la producció d'un text explicatiu.

\section{Objectius}

- Simular el procés d'absorció dels nutrients (glucosa) al budell prim

- Relacionar el procés de digestió i d'absorció intestinal amb polímers i monòmers respectivament, identificant-los amb colorants específics

- Considerar l'acció dels enzims hidrolítics en el procés digestiu

- Interpretar el procés de l'absorció intestinal a nivell molecular mitjançant una simulació

- Estructurar els conceptes al voltant de la digestió i absorció a través d'un mapa conceptual

- Comunicar el treball realitzat produint un text explicatiu

\section{ACTIVITAT 1 (LABORATORI)}

En aquesta activitat volem estudiar experimentalment quins tipus de molècules passen o no a la sang, després del procés de digestió a l'aparell digestiu.

\section{Procediment}

\section{Pas 1:}

Aconseguirem el budell d'un animal buidant una salsitxa. Utilitzarem la tripa que l'envolta per a simular el procés d'assimilació dels nutrients.
Lligarem un dels extrems del budell amb un cordill $i$ en l'altre extrem hi posarem una xeringa (sense l'èmbol), i també ho fixarem amb el cordill.

Mitjançant la xeringa introduïm dins del budell, una solució de midó a la qual hem afegit unes gotes de Lugol.

Submergim el budell en un got de precipitats on hi ha aigua destil-lada amb unes gotes de solució de Fehling, a uns $37^{\circ} \mathrm{C}$.

Mireu la imatge següent i descriviu els elements assenyalats:

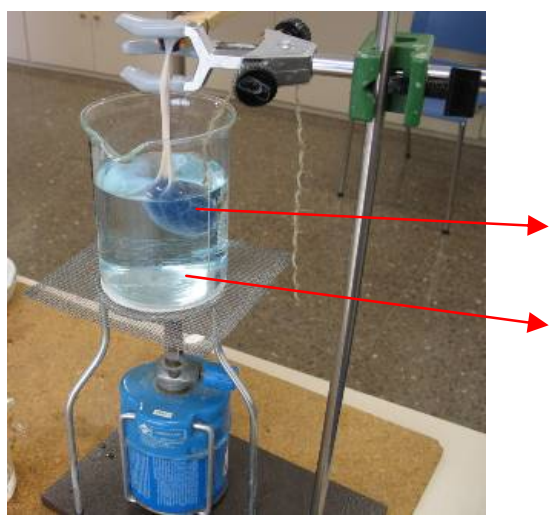

El Lugol i el Fehling són reactius que ens ajuden a identificar diferents compostos d'una manera específica. A la fig. 2 veuràs els colors que produeixen aquests dos reactius segons amb quins compostos reaccionen. 


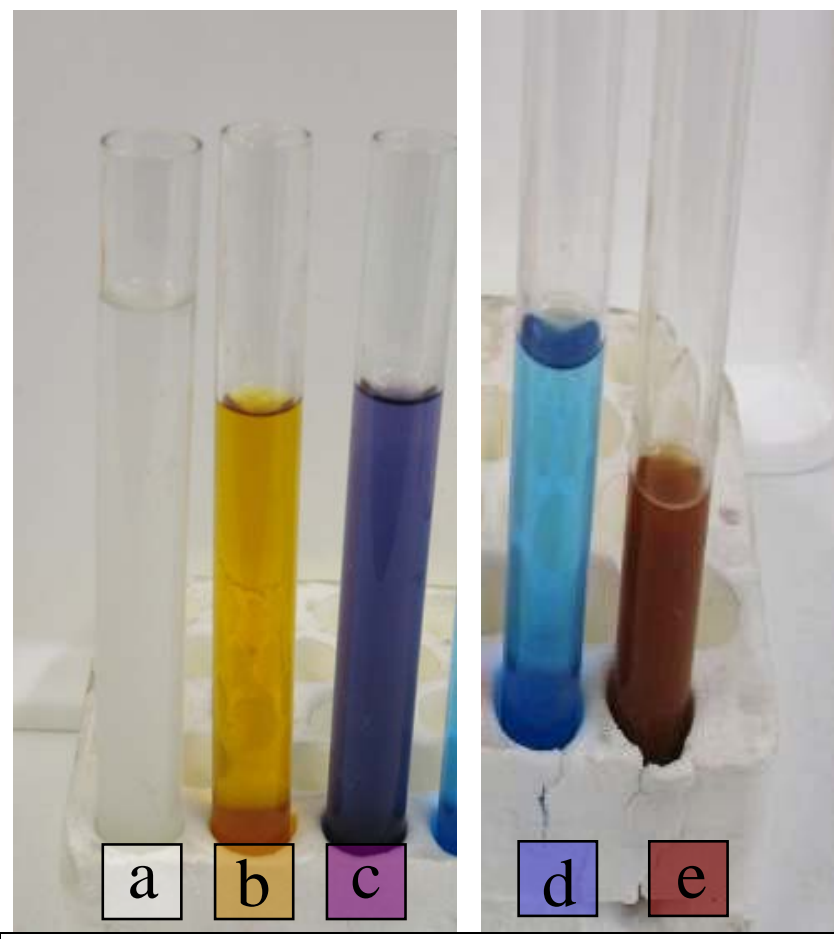

Figura 2. a) Solució de midó. b) Solució de Lugol. c) Solució de midó + Lugol. d) Solució de Fehling. e) Solució de glucosa + Fehling.

Fixeu-vos-hi bé i després intenteu contestar les preguntes següents:

- Completeu la taula següent:

\begin{tabular}{|c|c|c|c|c|}
\hline & & \multicolumn{3}{|c|}{ Solució } \\
\hline & & Midó & Glucosa & $\mathrm{H}_{2} \mathrm{O}$ \\
\hline \multirow{2}{*}{ 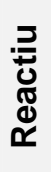 } & Lugol & $\begin{array}{c}\text { Violeta } \\
(+)\end{array}$ & & Groc fosc \\
\hline & Fehling & & $\begin{array}{c}\text { Vermell } \\
(+)\end{array}$ & \\
\hline
\end{tabular}

- Què creieu que simula l'aigua que hi ha al vas de precipitats?

- Per què el contingut del budell és de color violeta?

- Observeu durant 10 minuts el budell submergit en l'aigua destil.lada a $37^{\circ} \mathrm{C}$. Hi noteu algun canvi? Està passant alguna cosa pel que fa al procés de digestió i absorció? Per què?

- Per què l'aigua destil.lada del vas de precipitats continua de color blau cel?

- Què cal afegir, i on, perquè es produeixi algun canvi? (Recordeu que estem parlant de la digestió dels aliments).
Pas 2:

En un morter farem una solució de Pancreoflat. Hem de triturar una càpsula d'aquest medicament $\mathrm{i}$ dissoldre-la amb $50 \mathrm{ml}$ d'aigua destil.lada.

\section{Què és aquest medicament?}

En aquestes càpsules hi ha diversos enzims digestius. Aquests enzims serveixen per dividir, trencar, les molècules grans, com ara el midó, les proteïnes o els lípids, en els seus constituents més senzills, els seus monòmers.

En aquest cas l'enzim que interessa és l'amilasa pancreàtica.

- Què creieu que fa aquest enzim?

Amb l'ajut de la xeringa, introduïu la solució de pancreoflat dins el budell. I observeu què passa.

- Descriviu els canvis que aneu observant (dins del budell) i expliqueu per què passen.

Al cap de 10 minuts, enlaireu una mica el budell (perquè no rebenti) per sobre de l'aigua, i escalfeu el contingut del vas de precipitats.

- Descriviu els canvis que tenen lloc a l'aigua destil.lada. Per què passen?

- Observeu les següents imatges, ordeneu-les i comenteu el que passa a cadascuna d'elles:

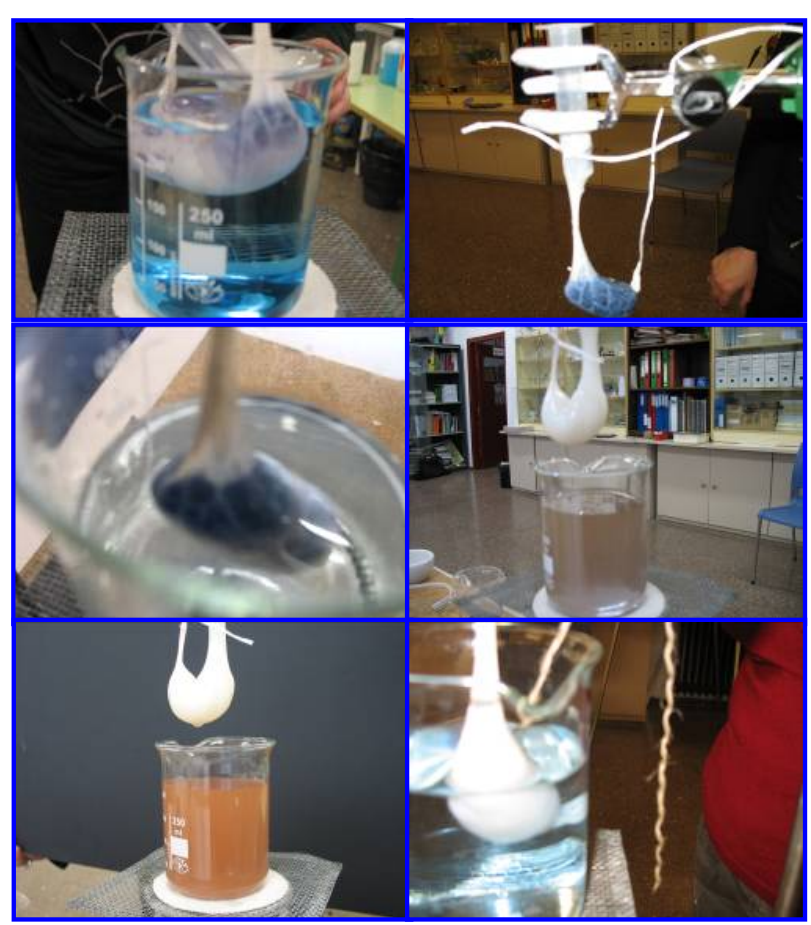




\section{ACTIVITAT 2 (SIMULACIÓ)}

\section{Voleu saber com s'absorbeix la glucosa a nivell molecular?}

Obriu la presentació PPS "Què passa amb els aliments després de la seva digestió?" (secció suplement d'aquest mateix número) i seguiu tot el procés, a través de les diferents diapositives.

\section{POSEM-HO TOT EN ORDRE!!}

\section{a. Estructuració}

Un cop duta a terme l'activitat de laboratori i observada la simulació PPS, hauríeu de ser capaços de completar el següent mapa conceptual que intenta estructurar tots els conceptes i els processos que tenen lloc des de la ingestió del midó fins l'absorció de la glucosa al budell prim.

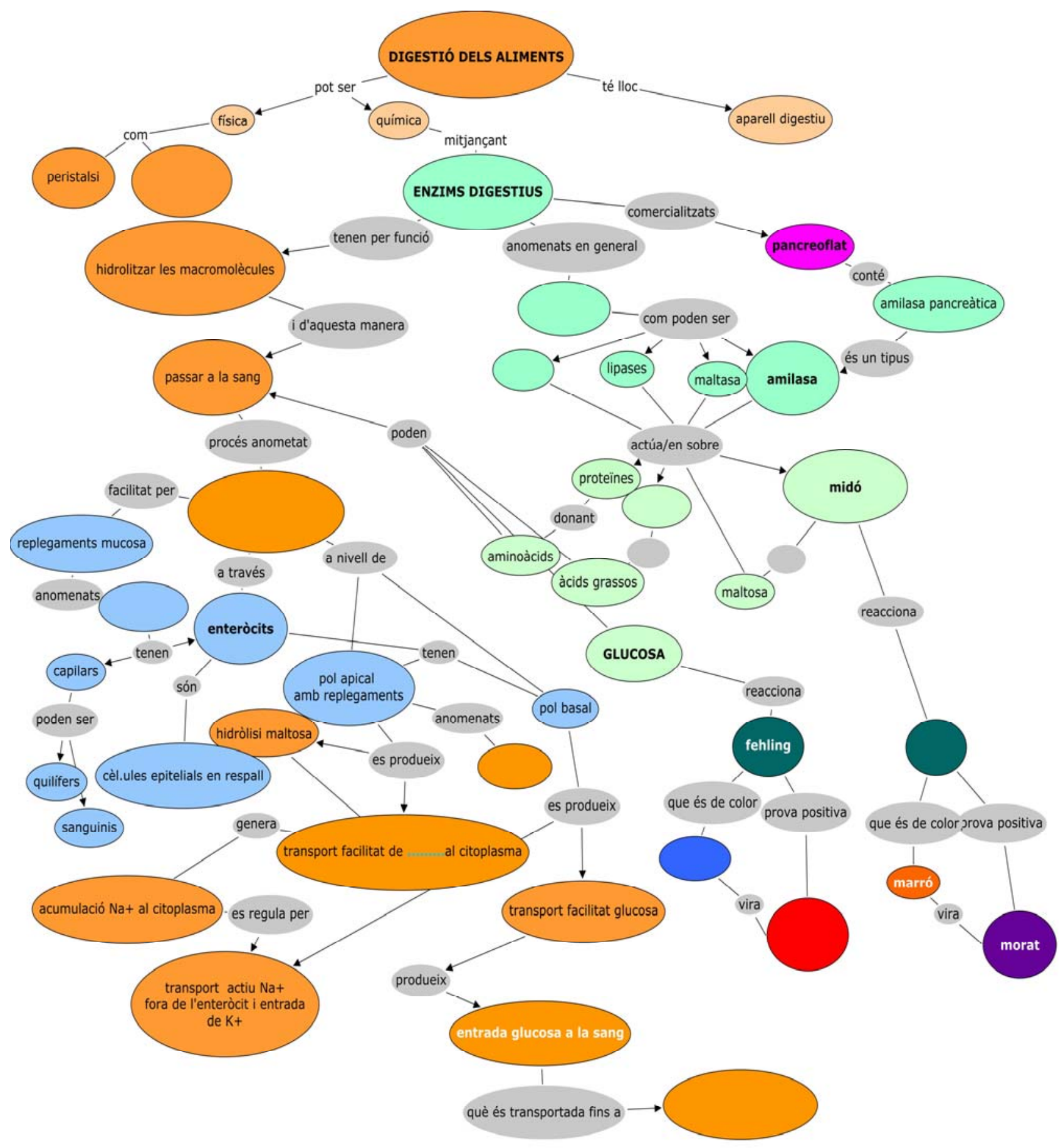




\section{b.- Comunicació}

Imagineu-vos que heu d'escriure un text explicatiu sobre la digestió i l'absorció dels glúcids, en una revista científica del país. Amb l'ajut de la base d'orientació que adjuntem, escriviu aquí el vostre text.

\begin{tabular}{|c|c|}
\hline Operacions: què he de fer & Estarà ben fet si... \\
\hline $\begin{array}{l}\text { - Repassar amb deteniment les activitats que he } \\
\text { fet } \\
\text { - Comprovar bé que sé de què he de parlar }\end{array}$ & $\begin{array}{l}\text { - Comprenc el que se'm demana } \\
\text { - Comprenc el significat de les paraules de les ac- } \\
\text { tivitats }\end{array}$ \\
\hline $\begin{array}{l}\text { - Planificar el text } \\
\text { - Recollir les idees científiques, en brut (paraules, } \\
\text { fets) } \\
\text { - Les organitzo i decideixo l'ordre en què les expo- } \\
\text { saré, d'acord amb els tres apartats: introducció, } \\
\text { desenvolupament, conclusions. }\end{array}$ & $\begin{array}{l}\text { - Estructuro els conceptes, puc distingir els més } \\
\text { generals dels més concrets } \\
\text { - Soc capaç de distingir el més important del més } \\
\text { accessori } \\
\text { - Els conceptes més generals els situo a la intro- } \\
\text { ducció, els més concrets, encara que siguin molt } \\
\text { importants, els situo al desenvolupament }\end{array}$ \\
\hline - Revisar el punt anterior & $\begin{array}{l}\text { - No m'he deixat cap concepte important } \\
\text { - Estic segur que l'ordre d'exposició és apropiat }\end{array}$ \\
\hline $\begin{array}{l}\text { - Començar a escriure el text d'acord amb la plani- } \\
\text { ficació (introducció) }\end{array}$ & $\begin{array}{l}\text { - La frase inicial recull el o els conceptes princi- } \\
\text { pals de l'enunciat } \\
\text { - Faig servir adequadament paraules per comen- } \\
\text { çar com: en primer lloc, d'entrada o altres com } \\
\text { per exemple, és a dir, etc }\end{array}$ \\
\hline - Continuar escrivint el desenvolupament & $\begin{array}{l}\text { - Totes les parts del text estan lligades. Es relaci- } \\
\text { onen amb connectors com: per perquè, ja que, } \\
\text { gràcies a, a causa de, en canvi, al contrari }\end{array}$ \\
\hline - Redacto la part final ( conclusió) & $\begin{array}{l}\text { - Indiquen el final amb per exemple: començar } \\
\text { amb: per acabar, finalment, en conclusió... } \\
\text { - Exposo alguna idea de globalitat o síntesi }\end{array}$ \\
\hline - Després d'escriure el text, revisar-lo. & $\begin{array}{l}\text { - Té sentit des del punt de vista científic } \\
\text { - És complet: } \\
\text { a) Cita tots els processos que tenen lloc a } \\
\text { l'aparell digestiu } \\
\text { b) Inclou el lloc, les molècules i estructures } \\
\text { que hi participen } \\
\text { c) Concreta per a què serveix tot aquest pro- } \\
\text { cés de digestió i absorció } \\
\text { - Una altra persona, un company/a de classe, ho } \\
\text { entendria bé }\end{array}$ \\
\hline
\end{tabular}




\section{CONCLUSIONS}

Durant la digestió al llarg de l'aparell digestiu els aliments són hidrolitzats per enzims específics, com l'amilasa pancreàtica, trencant-los en els monòmers corresponents; en el nostre cas, la glucosa. És així com aquestes "petites" molècules, franquegen les membranes dels enteròcits -les cèl.lules de les vellositats intestinals- $i$ entren als capil-lars sanguinis. A nivell molecular el procés es realitza amb la intervenció, passiva en uns casos i activa en altres, de les proteïnes de la membrana plasmàtica dels enteròcits.

La comprovació d'aquest últim procés, l'absorció intestinal, es pot inferir a partir d'una experiència de laboratori, en la qual podem comprovar com el midó no passa a través de la paret del budell i en canvi si que ho fa la glucosa. Això es fa palès per les tincions específiques de polímers i monòmers.

\section{COMENTARIS PER AL PROFESSORAT}

\section{Activitat 1 (laboratori)}

Es pot fer com una activitat POE -predir, observar i explicar- organitzada per a tot el grup classe.

Caldrà que escriguin les prediccions, argumentant-les i les contrastin amb els resultats obtinguts. S'aconsella fer una posada en comú abans d'escriure les conclusions.

Pas 1. Identifiquem el midó amb Lugol i submergim el budell que el conté en d'un bany d'aigua destilllada, que simula la sang. A l'aigua hi posem Fehling, que li donarà un color blau mentre no hi hagi hidròlisi de midó. Quan es produeixi, el producte final d'aquesta hidròlisi, la glucosa, passarà a través de la paret del budell a "la sang", és a dir al vas de precipitats. Quan la glucosa surti cap al vas de precipitats, la solució virarà de blau a vermell.

Pas 2. Per tal que es produeixi la hidròlisi del midó, afegim al budell Pancreoflat, un agregat enzimàtic, que venen a les farmàcies, que conté amilasa pancreàtica, enzim que hidrolitza enllaços glucosídics que uneixen els monòmers de glucosa que formen el midó. S'aixafa una càpsula de Pancreoflat amb una mà de morter, es dissol en $10 \mathrm{ml}$ d'aigua i es passa al budell amb l'ajut de la xeringa.

De cop, el color morat del midó-lugol desapareix, ja que s'hidrolitza el midó i a poc a poc l'aiguafehling del vas de precipitats va virant a vermell (fehling positiu amb glucosa).
Per no allargar aquest procés es pot aixecar el budell i escalfar més l'aigua-fehling, ja que la reacció serà més ràpida i es veurà el color vermell més aviat.

Mentre transcorren els 10 minuts, temps necessaris per realitzar-se la hidròlisi del midó i sortida de la glucosa al vas de precipitats, cal que els alumnes prediguin què passarà. Convé tractar i relacionar, aquí, el concepte de digestió, hidròlisi, enzim, enzim-substrat, especificitat enzimàtica, monòmers, absorció, pas a través de membranes...

El comentari que esperem de l'alumne/a hauria de ser com el que segueix: "Al budell, el midó ja s'ha hidrolitzat en glucosa, que és absorbida com els altres monòmers i així passa a la sang. Ho comprovem perquè identifiquem el polímer, el midó, i el seu monòmer, la glucosa, mitjançant els colorants que els caracteritzen. L'aigua del vas de precipitats mai no es tenyeix de morat; això vol dir que el midó no surt del budell. En canvi, després d'haver afegit l'enzim, sí que es tenyeix de vermell, la qual cosa demostra que la glucosa sí que ha passat".

\section{Activitat 2 (simulació)}

Després d'interpretar el procés de l'absorció intestinal al laboratori, a nivell d'òrgan, de sistema, es pot passar a treballar la simulació per observar com es produeix el procés d'absorció a nivell cel.lular i molecular.

Quan s'arriba a la pantalla dels enteròcits de l'epiteli intestinal cal fer atenció al pas de la glucosa a través de la proteïna transmembrana que realitza la "difusió facilitada" d'aquella. Observeu com passen dos ions sodi mentre passa una molècula de glucosa.

Un cop la glucosa és dins de la cèl.lula epitelial, cal que surti pel pol bassal cap als capil-lars sanguinis. Un altre cop es realitza per difusió facilitada per una proteïna transmembrana.

Pel que fa als ions sodi, que s'havien acumulat en excés al citoplasma, surten a través de la "bomba Na-K", per transport actiu un altre cop a l'exterior, recuperant la cèll.lula el seu estat inicial.

Un cop a la sang, la glucosa serà distribuïda a totes les cèl-lules de l'organisme.

El mapa conceptual intenta estructurar tot el que s'ha treballat al laboratori i a la simulació.

Després d'això cal que escriguin unes conclusions coherents, per la qual cosa facilitem a l'alumne una base d'orientació que "l'acompanyi" en el procés de redactar un paràgraf explicatiu. 


\section{BIBLIOGRAFIA}

CUSTODIO, E. (2002). Enseñar a justificar en la clase de ciencias: una oportunidad que no podemos desaprovechar. Aula, n. 116.

SANMARTÍ, N. (coord.) (2002). Aprendre ciències tot aprenent a escriure ciències. Barcelona: Edicions 62.
GUYTON, A.C. i HALL, J.E. (2000). Textbook of Medical Physiology. 10 th edition W.B. Sauders Co., Philadelphia.

BOWEN, R.A.. (2005) Biomedical Sciences. Digestive System. Colorado State University.

http://arbl.cvmbs.colostate.edu/hbooks/pathphys /digestion/index.html

FELDMAN's GastroAtlas On line

http://www.gastroatlas.com/login.aspx 